\title{
Das Schicksal des Glykokolls im Organismus des Hundes bei intravenöser Einverleibung.
}

\author{
Von
}

S. Salaskin und Kath. Kowalevsky.

(Aus dem physiol.-chem. Laboratorium der medizinischen Hochschule für Frauen in St. Petersburg.)

(Der Redaktion zugegangen am 15. Juli 1904.)

In der Arbeit des einen von uns, welche in Gemeinschaft mit Zaleski und Horodynski ${ }^{1}$ ) veröffentlicht worden ist, war gesagt worden, daß wir beabsichtigen, weitere Untersuchungen über die Entstehung und das Schicksal des Ammoniaks im Tierkörper und über das Verhalten der Leber zu diesem Prozesse vorzunehmen. Einen Teil dieser Aufgabe zu lösen, haben Kath. Kowalevsky und M. Markewicz übernommen; ihre Arbeit hat fast ihr Ende erreicht, da jedoch M. Markewicz aus äußeren Gründen zu Ende des vorigen Jahres die Arbeit zeitweilig einstellen mußte, so kann sie gegenwärtig noch nicht veröffentlicht werden, weshalb wir beschlossen haben, fürs erste über die Ergebnisse unserer mit Glykokoll angestellten Versuche zu berichten, umsomehr als sie die Ergebnisse, zu denen Stolte ${ }^{2}$ ) in seiner Arbeit gelangt ist, in gewissem Maße ergänzen.

Das Schicksal des Glykokolls interessierte uns namentlich aus folgenden Gründen: Schultzen und Nencki, ${ }^{3}$ ) ebenso wie auch Salkowski) haben nachgewiesen, daß das Hunden gefütterte Glykokoll im Harn als Harnstoff ausgeschieden wird; weiter ersieht man aus den Untersuchungen von Salaskin, ${ }^{5}$ )

1) Diese Zeitschrift, Bd. XXXV, S. 246.

2) Hofmeisters Beiträge, Bd. 5, S. 15.

3) Ber. d. d. chem. Gesellsch., Bd. 2, S. 580.

4) Diese Zeitschrift, Bd. IV, S. 55 und 110.

5) Diese Zeitschrift, Bd. XXV, S. 128. 
daß die Leber die Fähigkeit besitzt, das Glykokoll in Harnstoff oder einen diesem nahestehenden Körper ${ }^{1}$ ) umzuwandeln, und aus Versuchen desselben Autors ${ }^{2}$ ) ist bekannt, daß das Glykokoll bei Hunden mit Eckscher Fistel bei innerlicher Eingabe die Entwickelung der charakteristischen Vergiftungserscheinungen infolge von Ammoniakanhäufung im Blute hervorruft. Schließlich hat Hofmeister ${ }^{3}$ ) nachgewiesen, dab durch Oxydationssynthese aus Glykokoll in Gegenwart von Ammoniak Harnstoff entstehen kann. Es fragt sich nun, wie diese Umwandlung von Glykokoll in Harnstoff sich im Organismus abspielt: findet sie infolge von oxydativer Synthese im Sinne Hofmeisters statt, oder muß sich das Glykokoll erst unter Ammoniakentwickelung zersetzen und dann erst durch Anhydrierung von kohlensaurem, resp. karbaminsaurem Ammoniak in Harnstoff umwandeln? Man kann natürlich auch annehmen, daß das durch Glykokollzersetzung gebildete Ammoniak mit irgend einer stickstofffreien Substanz, ebenfalls durch oxydative Synthese (siehe Hofmeister 1. c.), Harnstoff bildet. Unsere Versuche sollten eben diese Frage entscheiden, da sie allein aber nicht dazu genügen, so untersuchen wir gegenwärtig die Produkte, welche bei Oxydation von Phenylglycin außerhalb des Organismus entstehen, und studieren sein Schicksal bei Durchblutung der ausgeschnittenen Leber, sowie das Schicksal der Oxanylsäure bei Fütterung von Hunden und bei Durchblutung der Leber. Die Idee, zum Zwecke der Lösung dieser Frage sich des substituierten Harnstoffs zu bedienen, gehört Nencki und Schultzen ${ }^{4}$ ) an, jedoch haben sowohl ihre Versuche, als auch die Versuche von Rosenfeld ${ }^{5}$ ) gezeigt, daß das Phenylglycin für Tiere giftig ist, und deshalb suchen wir, indem wir an der Idee festhalten, sie in anderer Weise zu verwirklichen.

Wir gehen nun zu unseren Versuchen mit intravenöser Einverleibung von Glykokoll an Hunden über. Die Tiere wurden

1) Loewi, Diese Zeitschrift, Bd. XXV, S. 511.

2) Diese Zeitschrift, Bd. XXV, S. 449.

s) Arch. f. exp. Path. u. Pharmak., Bd. 37, S. 426.

$\left.{ }^{4}\right)$ l. c.

5) Hofmeisters Beiträge, Bd. 4, S. 379.

Hoppe-Seyler's Zeitschrift f. physiol. Chemie. XLII. 
mit Morphium narkotisiert; die Lösung wurde ganz allmählich und abwechselnd aus zwei Büretten in die Venen gebracht, sodaß die Injektion ohne Unterbrechung und gleichmäßig stattfand. Das Glykokoll bestimmten wir im Blut und im Harne nach der Methode von Fischer, ${ }^{1}$ ) die später auch von Abderhalden und Bergell ${ }^{2}$ ) angewandt wurde; wir bedienten uns hierbei des $\beta$-Naphtalinsulfochlorids, welches wir aus $\beta$-naphtalinsulfosaurem Natron und Phosphorpentachlorid darstellten. Das Ammoniak wurde nach der Methode von Nencki und Zaleski bestimmt.

\section{Versuch 8. 20. V. 1903.}

Gewicht des Hundes 22,35 kg. Vor dem Versuche 24stündige Hungerperiode. Vor dem Versuch wurde der Harn mit dem Katheter entleert. Es wurden $430 \mathrm{ccm}$ Lösung mit einem Gehalt von $14,3 \mathrm{~g}$ Glykokoll $=3,2 \mathrm{NH}_{3}$ im Laufe von $43 \mathrm{Mi}$ nuten injiziert; in einer Minute wurden also auf $1 \mathrm{~kg}$ Gewicht des Tieres 14,19 $\mathrm{mg}$ Glykokoll $=3,3 \mathrm{mg} \mathrm{NH}_{3}$ einverleibt.

In $100 \mathrm{~g}$.

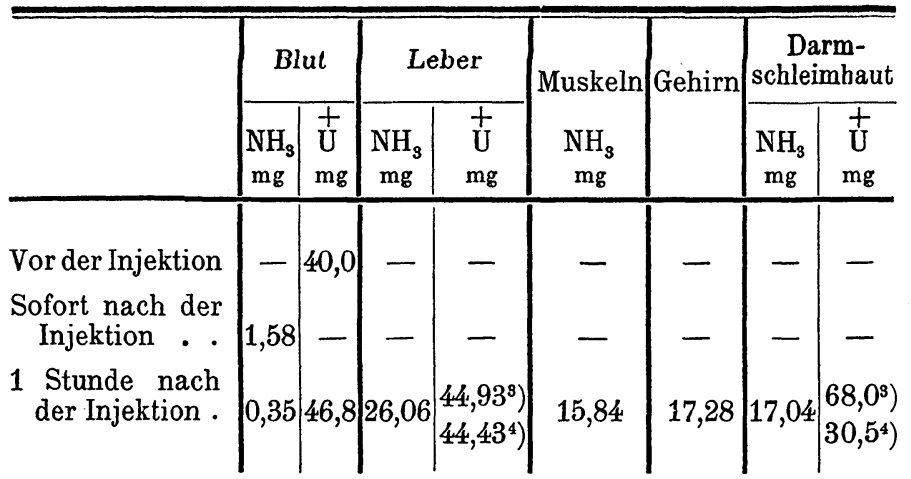

1) Ber. d. d. chem. Gesellsch., Bd. 35, S. 3779.

2) Diese Zeitschrift, Bd. XXXIX, S. 9 u. 464.

8) Nach Schöndorff-Braunstein bestimmt.

4) Nach Mörner-Folin bestimmt. Die Differenz bei der $\mathrm{NH}_{3}$ Bestimmung in der Darmschleimhaut beweist, daß sich hier außer Harnstoff noch ein anderer Körper vorfindet, welcher bei Bestimmungen nach Mörner-Folin keinen $\mathrm{NH}_{3}$ abspaltet. Überhaupt ist die Methodik der Harnstoffbestimmung eine sehr mangelhafte. 
- Das Schicksal des Glykokolls im Organismus des Hundes.

\section{Versuch 16. 2. XI. 1903.}

Gewicht des Hundes 17,25 kg. Vor dem Versuche 24stündige Hungerperiode. Kurz vor der Injektion wurde das Tier katheterisiert. Injiziert wurden $440 \mathrm{ccm}$ Lösung mit einem Gehalt von 17,6 g Glykokoll $=4,0 \mathrm{~g} \mathrm{NH}_{3}$ im Laufe von 29 Minuten. In der Minute wurde also auf $1 \mathrm{~kg}$ Gewicht des Tieres $352 \mathrm{mg}$ Glykokoll $=8,1 \mathrm{mg} \mathrm{NH}$ einverleibt. $100 \mathrm{~g}$ Blut enthielten vor der Injektion $0,51 \mathrm{mg} \mathrm{NH}_{3}$, sofort nach der Injektion $1,16 \mathrm{mg}$, eine Stunde nach der Injektion $1,15 \mathrm{mg}$. Im Laufe des Versuches wurde der Harn mehrmals mit dem Katheter entleert.

Harnanalyse (Reaktion alkalisch).

\begin{tabular}{c|c|c|c|c|c}
\hline \hline & & Gesamt-N & $\frac{\mathrm{N}\left(\mathrm{NH}_{8}\right)}{\mathrm{N}}$ & $\frac{\mathrm{N}(\mathrm{U})}{\mathrm{N}}$ & $\begin{array}{c}\beta-N a p h t a l i n- \\
\text { sulfoglycin }\end{array}$ \\
\hline $\begin{array}{c}40 \text { Minuten nach } \\
\text { Beginn der Injektion } \\
60 \text { Minuten nach } \\
\text { Beginn der Injektion } \\
\begin{array}{c}\text { 1 Std. 29 Min. nach } \\
\text { Beginn der Injektion }\end{array}\end{array}$ & $53 \mathrm{ccm}$ & 0,2788 & $3,3 \%$ & $25,14 \%$ & $2,0798 \mathrm{~g}$ \\
\hline
\end{tabular}

Was das Vorhandensein von Glykokoll in Blut, Leber, Muskeln, Nieren und Darmschleimhaut anbetrifft, so ergaben die diesbezüglichen Bestimmungen ein negatives Resultat, während das Glykokoll in Kontrollversuchen, wo es in geringen Mengen $(0,25-0,5 \mathrm{~g})$ dem Blute und den Organen hinzugefügt wurde, nach der Methode von E. Fischer sehr leicht entdeckt werden konnte.

Die angeführten Versuche berechtigen zu folgenden Schlußfolgerungen :

1. Einmalige Injektion von bedeutenden Glykokollmengen ins Blut bedingt erhöhten $\mathrm{NH}_{3}$-Gehalt dieses letzteren.

2. Das Blut entledigt sich des Glykokolls sehr rasch, indem es dasselbe teilweise (zum geringeren Teile) mit dem Harne ausscheidet, teilweise aber den Geweben abgibt.

3. Die Tatsache, daß Glykokoll unter den Versuchsbedingungen in den Geweben nicht ausfindig zu machen ist, läßt 
414 S. Salaskin u. Kath. Kowalevsky, Glykokoll des Hundes.

vermuten, daß es dort Umwandlungen erfährt; am nächsten liegt der Gedanke, daß es unter $\mathrm{NH}_{3}$-Entwickelung zersetzt wird, worauf die $\mathrm{NH}_{3}$-Anhäufung im Blute, sowie Salaskins ${ }^{1}$ ) Versuch mit Glykokollfütterung von Hunden mit Eckscher Fistel hindeutet. Die Umwandlung des einverleibten Glykokolls, jedenfalls des größten Teiles desselben, in Harnstoff findet also augenscheinlich in der Weise statt, daß sich aus ihm zuerst kohlensaures, resp. karbaminsaures Ammoniak entwickelt.

Vielleicht wird es gelingen, diese Frage in unseren Versuchen mit Phenylglycin und Oxanylsäure mit größerer Exaktheit $\mathrm{zu}$ entscheiden.

i) 1. c. 